\title{
Design of Nutrition Automation on Lactuca Sativa NFT Hydroponic Systems
}

\author{
$1^{\text {st }}$ Joko Slamet Saputro \\ Department of Electrical Engineering \\ Universitas Sebelas Maret \\ Surakarta, Indonesia \\ jssaputro89@staff.uns.ac.id
}

\author{
$2^{\text {nd }}$ Ulinnuha Latifa \\ Electrical Engineering Dept \\ University of Singaperbangsa \\ Karawang \\ Karawang, Indonesia \\ ulinnuhalatifa@gmail.com
}

\author{
$3^{\text {rd }}$ Agus Ramelan \\ Department of Electrical Engineering \\ Universitas Sebelas Maret \\ Surakarta, Indonesia \\ agusramelan@staff.uns.ac.id
}

\begin{abstract}
This research focus on preserved nutrition on lettuce plants, as well as automation of other parameters that affect plant growth in NFT type hydroponic systems such as temperature, water acidity $(\mathrm{pH})$, water level and light intensity. The automation of this hydroponic system includes the provision of nutrients according to the needs of plants by utilizing EC sensors, keeping the temperature of the water in accordance with plant specifications as well as water levels that are maintained.
\end{abstract}

Keywords - hydroponics, NFT, nutrition automation

\section{INTRODUCTION}

Indonesia is an agrarian country with the majority of its population working as farmers. This is supported by Indonesia's strategic location which is on the equator line so that it gets enough sunshine throughout the year [1]. In addition, one third of Indonesia's territory consisting of waters increasingly supports Indonesia as an agricultural country.

One of the fields that is currently being promoted is hydroponic agriculture. Hydroponics is an agricultural method that uses planting media in the form of water or liquid that is rich in plant nutrition. Media that can be used include water, pearlite, clay pellets, and peat moss. The main purpose of this hydroponic system is to make plant roots in direct contact with nutrients while getting enough oxygen to optimize plant growth [2]. The basic concept of hydroponics can be understood by looking at Figure 1 .

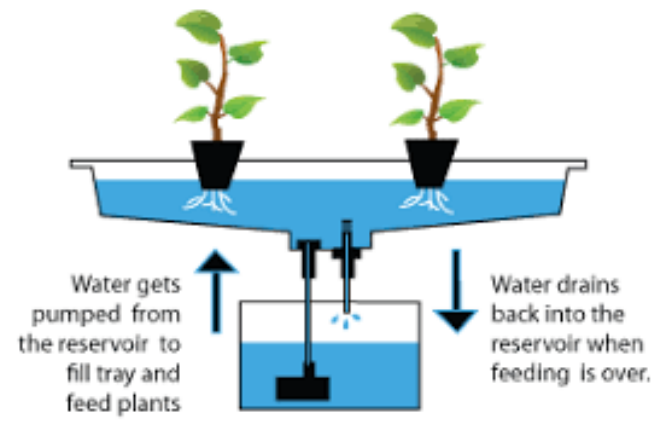

Fig. 1. Basic concept of hydroponic

The concept of hydroponic agriculture has criteria and methods that are quite different from conventional agriculture. This is related to different planting media so that some special treatments are needed including temperature and nutrition that must be maintained in addition to the $\mathrm{pH}$ of the growing media which also has a special standard. For this reason, a monitoring and scheduling system is needed so that the system can run more optimally.
In this research discussed about optimization of hydroponic farming systems. This optimization is expected to be achieved by designing an automation system that is able to control temperature and nutrients in the growing media. in addition, a $\mathrm{pH}$ monitoring system is also designed. The types of plants that is used as research objects are lettuce. This plant is used to complement the factors, besides that this plant is also an icon of the hydroponic process.

\section{MATERIAL AND METHODS}

The hydroponic system that was built in this study uses a type of Nutrient Film Technique with a circulating irrigation system. This type is chosen because it is considered to have high effectiveness in the distribution of nutrients and oxygen so that plants can grow more optimally [3].

The Nutrient Film Techinque, or NFT, is a kind of hydroponic system where the flow of nutrient solutions constantly flows through the roots of plants [2]. The channel pipe is slightly tilted so that the nutrient solution will flow with gravitational force. This type of system works very well because the plant roots absorb more oxygen from the air than from the nutrient solution itself. Because only the root tips come into contact with nutrient solutions, these plants are able to get more oxygen so that the growth rate is faster.

Irrigation is designed using a water pump by placing a water level sensor at several points to control water circulation. In addition, to regulate nutrients absorbed by plants, EC sensors and $\mathrm{pH}$ sensors are used. The EC sensor will detect the level of nutrients in the liquid and the $\mathrm{pH}$ of the sensor will provide $\mathrm{pH}$ liquid data to ensure that plant growth will not be disturbed. Setting the liquid temperature is done by using a temperature sensor with an actuator in the form of a cooler or water heater [4].

\section{A. NFT Hydroponics Design}

The initial stage in this study was to prepare a hydroponic system as a planting medium. The hydroponic system used is NFT type, because in this system it is possible that each plant will get the first water supply directly from the nutrient tank.

The design of the NFT system used materials including; (1) plastic pipes of varying sizes as the frame and systems of nutritious water supply (2) water tank which are engineered to become a media for lettuce plants in 2 lines; (3) plastic basin as the nutritious water containers that will be channeled to plants and as a place for reversed water from plants. The hydroponic media of the NFT system has been designed as shown in the figure 2 . 


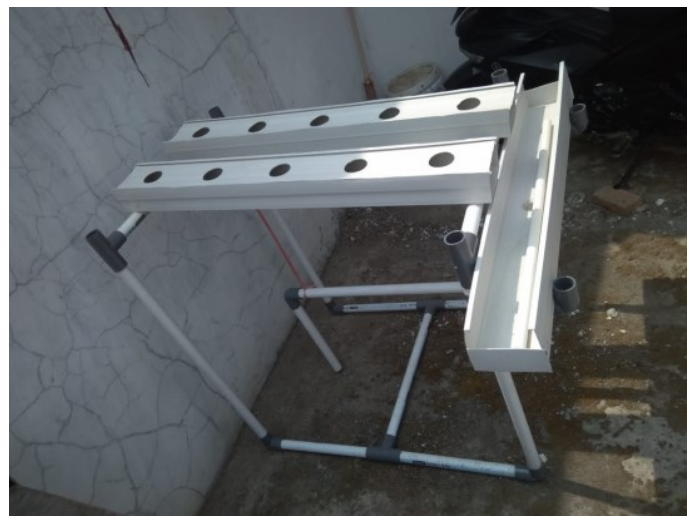

Fig. 2. NFT Design

\section{B. Control Design}

The design of control system in this research can be seen in figure 3.

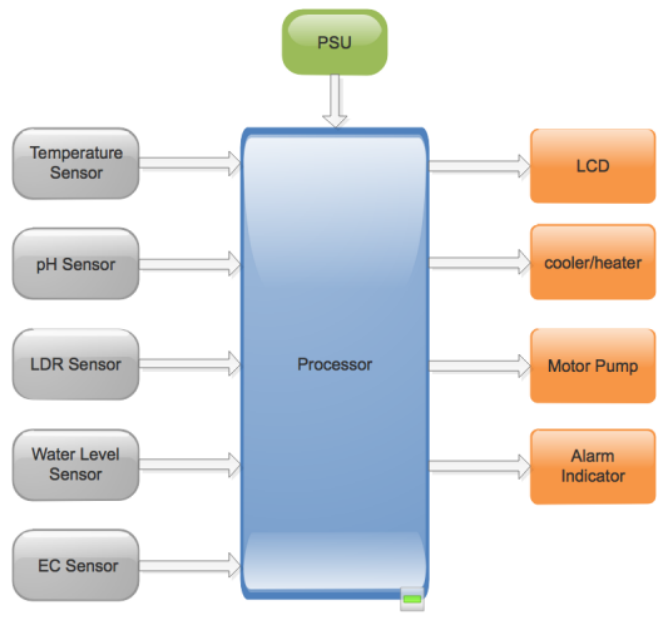

Fig. 3. Diagram of control design of hydroponic system

The diagram that showed implementation of control system can be seen in figure 4 and figure 5 .

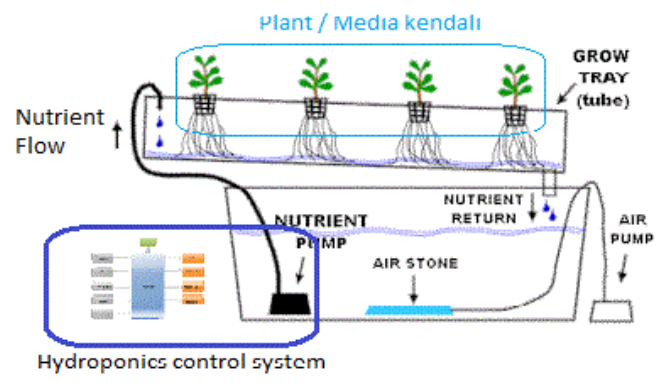

Fig. 4. Diagram of control design of NFT hydroponic system

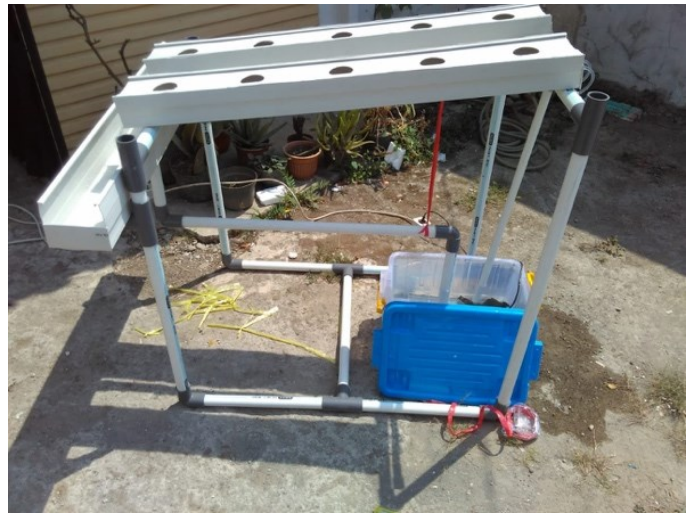

Fig. 5. Control implementation

According to figure 3, description of each component are:

1. Processor, used as the brain of the control system. The device that was used is Arduino Mega.

2. PSU, power supply unit.

3. Temperature sensor, used as temperature detector. The type of sensor that was used is water temperature sensor.

4. LDR, Light dependent resistor, used to detect sunshine intensity.

5. Water level sensor, to detect surface level in the tank and water pipe.

6. $\mathrm{pH}$ Sensor, to detect the $\mathrm{pH}$ of nutrition liquid in tank [5].

7. EC Sensor, Electrical conductivity sensor to detect EC of nutrition liquid in the pipe. The ideal EC of hydroponic are between 1.5 and $2.5 \mathrm{dS} / \mathrm{m}$. [4]

8. LCD, to display the experiment data.

9. Cooler/heater, as an actuator to controlling the temperature.

10. Alarm indicator, as an indicator of abnormality.

\section{Making Seeds}

The plants used as objects of research in this study were Red Lettuce and White Lettuce. The selection of these plants is due to ease of maintenance and a more significant harvest period compared to other plants. Before lettuce is planted into a hydroponic system, a preparation stage is needed, namely lettuce seedling. The seeding process starts from the seeds placed into the seedling planting media, the seeds are allowed to grow up to 2 weeks or have at least 4 leaves. After the seeding process, the lettuce seeds will be moved into the rockwol and placed into the tray in the hydroponic system. By the time it has been transferred into this hydroponic system in the hope that the plants are ready to grow by absorbing nutrients that are supported by the hydroponic nutrient flow system. 


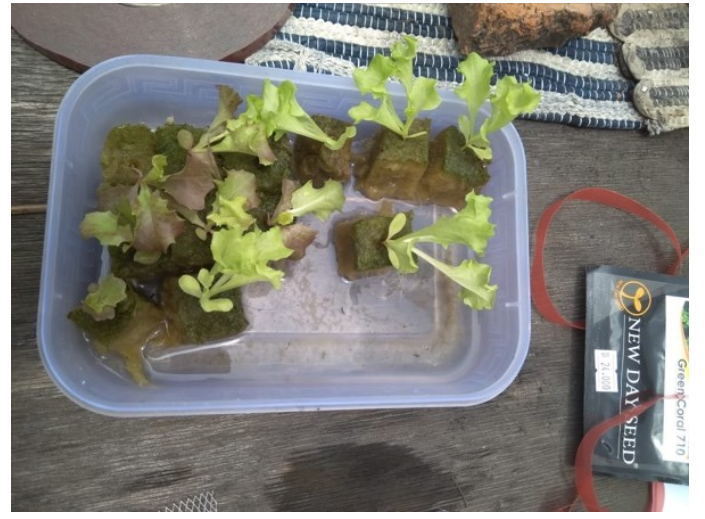

Fig. 6. Lettuce seeds

\section{RESULT AND DISCUSSION}

The results of the $\mathrm{pH}$ measurement of the planting media from November $4^{\text {th }}$ to $10^{\text {th }}$, which is the second week of planting. As for the following week until the harvesting period the acidity characteristics $(\mathrm{pH})$ of the planting medium were the same at the 2 nd week. In figure 6 , it can be seen that the acidity $(\mathrm{pH})$ of the growing media is in accordance with the ideal conditions needed by lettuce to grow optimally, 6-7. Also seen is the increase in $\mathrm{pH}$ measured during the sensor initialization process, so that the characteristics of the sensors used are known. The grafic show in Figure 7.

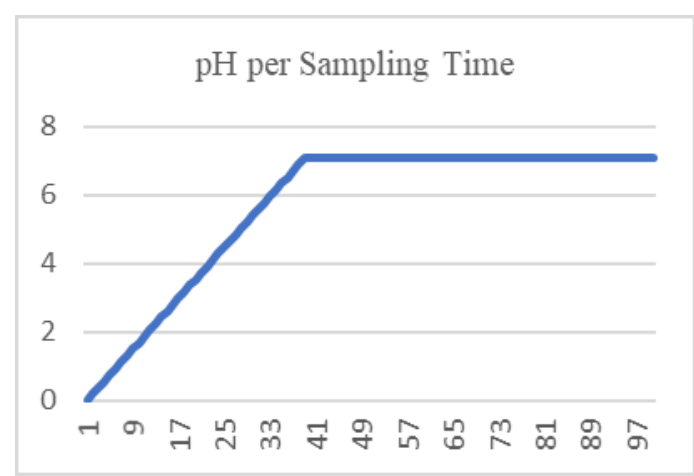

Fig. 7. Acidity data on planting media

The measurement result of the sensor TDS (Total Dissolve Solid) which is the data of nutrient levels in the planting media with units of ppm (parts per million). The Data taken seen that the nutrient content of the planting media was always in the desired ideal condition, namely 840 with a tolerance value of $50 \mathrm{ppm}$ (shown in figure 8).

The nutrients used in this planting medium use $A B$ mix in the form of liquid, while the process of providing nutrients to the planting media tub is carried out automatically which is regulated by the submiser motor control device with a ratio of $1 \mathrm{ml}: 10 \mathrm{ppm}$.

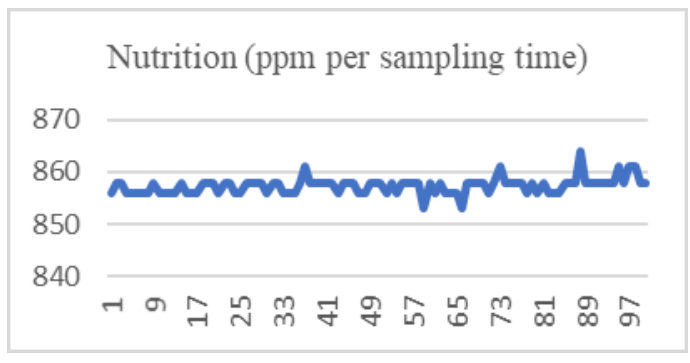

Fig. 8. Nutrition data on planting media

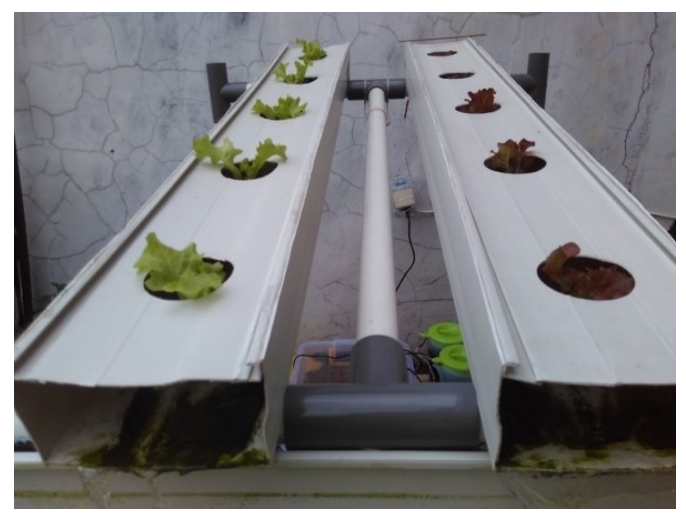

Fig. 9. Plant growth the first week

The period of enlargement of lettuce into the hydroponic system starts on October 28. Figure 9 is a development picture at the first week. It appears that plant roots begin to spread and leaves begin to grow out of the hole even though some leaves was still a bud.

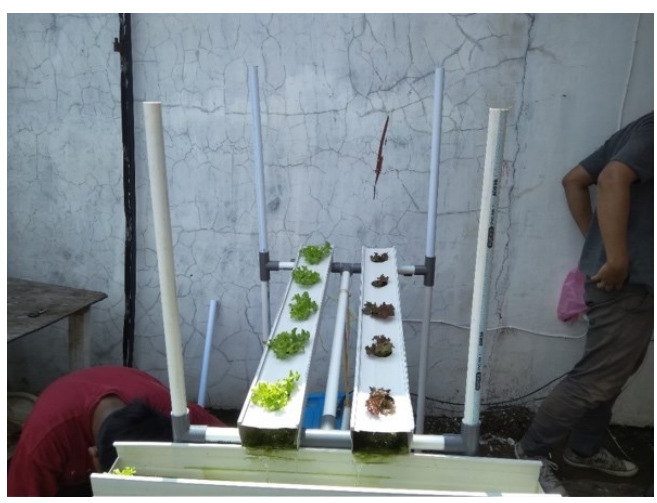

Fig. 10. Plant growth the Second week

Figure 10 is a development picture of the plant at the second week. It can be seen that the plant roots begin to extend and touch the planting media. The growth is more significant compared to the first week even though there are rain water factors that affect the lettuce leaves and make it limp/wilt. To overcome these problems it is necessary to add a roof that serves to absorb UV light and prevent direct lettuce contamination of rain water.

Because the lacked of sunshine, lettuce attacked by pests. On of the solution is by spreading the organic pesticides and maintain hydroponic environmental conditions away from other plants.

Figure 11 is a developmental image at the 3 rd week. It is seen that leaf growth is quite significant, this is because the nutrient intake of lettuce rises to $700 \mathrm{ppm}$ (based on the age 
of lettuce) besides that the presence of fiber roof can filter UV rays directly about the leaves and rainwater contamination.

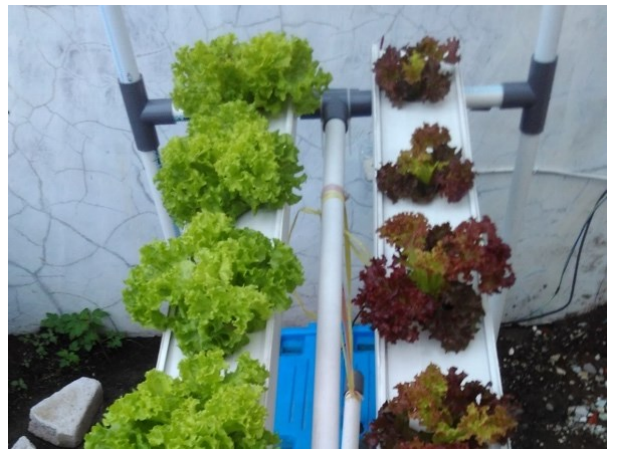

Fig. 11. Plant growth the third week

(a)

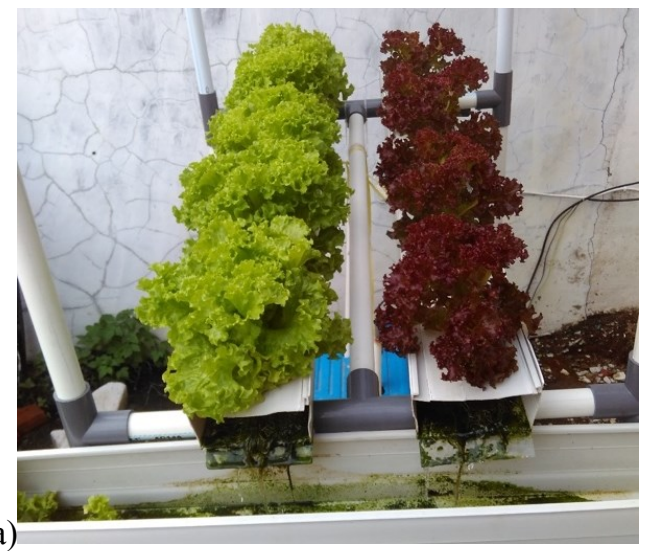

(b)

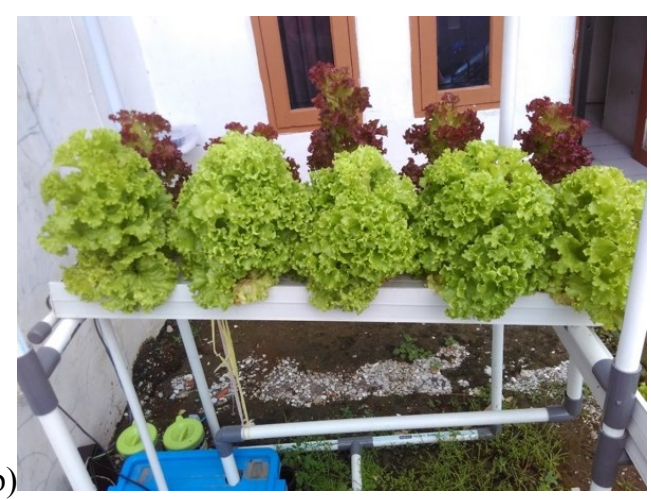

Fig. 12. (a) Plant growth the fourth week and (b) Plant growth the fifth week

In a 4th week, plants seen that growth fastly because nutrient levels rised according to nutritional needs. Figure 12.(b) is a developmental image at the fifth week. It appears that the growth is at the peek point and it's time to harvest.

\section{CONCLUSION}

Based on this research can be concluded that:

1. The acidity $(\mathrm{pH})$ of the planting media is in accordance with the ideal conditions needed by lettuce to grow optimally which is 6 until 7.

2. The nutrient content of the planting media was always in the desired ideal condition, namely 840 with a tolerance value of $50 \mathrm{ppm}$.
3. plants experience normal growth. only pests appear that require organic pesticides.

\section{ACKNOWLEDGMENT}

We thanks to LPPM Universitas Singaperbangsa Karawang for all the support.

\section{REFERENCES}

[1] Care Indonesia. (n.d.) icare-indonesia.org: https://icareindonesia.org/kajian-potensi-energi-surya-di-indonesia-2/

[2] Jones Jr, J. B. (1982). Hydroponics: its history and use in plant nutrition studies. Journal of plant Nutrition, 5(8), 1003-1030.

[3] Umi Fadlillah Umar, SP, M.Si, and Ydhan Nur Akhmadi, S.TP, MM, (2016), "Jago Bertanam Hidroponik Untuk Pemula", Jakarta Selatan; Agromedia

[4] Nalwade, R., \& Mote, T. (2017, May). Hydroponics farming. In Trends in Electronics and Informatics (ICEI), 2017 International Conference on (pp. 645-650). IEEE.

[5] Drive The Future Robot. (2016). Technical Spesification pH meter. 